Accelerator Division Departmental Procedure

AD/ Mechanical Support

ADDP-ME-000148

\title{
DEGREASING AND CLEANING SUPERCONDUCTING RF NIOBIUM CAVITIES
}

PREPARED BY: DATE:

Michael Rauchmiller, ADMS Senior Technician

PREPARED BY: DATE:

Ron Kellett, ADMS Senior Technician

APPROVED BY:

DATE:

Patrick Hurh, ADMS Head

Controlled Copy No.: 


\section{Review And Concurrence Record}

\section{REVIEWED BY: \\ DATE :}

Allan Rowe, ADMS Engineer

REVIEWED BY:

DATE :

Wade Muranyi, ADMS Senior Technician 


\section{Table of Contents}

1.0 PURPOSE AND SCOPE- 1

2.0 REQUIRED EQUIPMENT- 1

3.0 CLEANING PROCEDURE- 1

4. 0 ILLUSTRATIONS- 3 
1.0 PURPOSE AND SCOPE

Detail the steps necessary for degreasing and cleaning of superconducting RF Niobium cavities in the $A \emptyset$ clean room.

PRECAUTION: Extreme caution should be exercised whenever handling a cavity without a stabilizer frame or protective covers on the flanges. All persons involved should wear nitrile gloves at all times.

\subsection{REQUIRED EQUIPMENT}

The following items are needed to execute the degreasing procedure on the 9-cell cavity.

a. (1) 9-cell cavity.

b. (1) Tall ultra-sonic tank.

c. $(2395 \mathrm{ml})$ Micro $90 \AA$ detergent.

d. (4) Stainless steel wire hooks of the same size.

e. (1) 15 gallon rinse barrel.

f. (1) Stainless steel cross bar to fit the ultrasonic tank.

g. (1) Resistivity meter.

\section{3. $\odot$ CLEANING PROCEDURE}

It is important to follow each step in the following order:

a. Clean the tall ultrasonic tank and the 15 gallon rinse barrel using a weak solution of Micro and ultra pure deionized (DI) water. Rinse both thoroughly with DI water.

b. Fill the tall ultrasonic tank with DI water until it is above the overspill lip at the back of the tank. Add 2,395 milliliters of Micro Degreaser to the water.

c. Turn on the tank heater. The control is located on the lower right front of the tank. Adjust the control to $150^{\circ}$ Fahrenheit.

d. Turn the ultrasonic on. The switch for the ultrasonic is on a large gray box bolted to 
several green power supply boxes. These are setting on top of two other controllers and located to the far left side of the ultra sonic cleaning area by the shelves.

e. When the water reaches 150F, place the cavity in the ultrasonic tank. Turn off the ultrasonic before submersing the cavity in the tank. Gently lower the cavity into the tank tipping it from side to side to remove all of the air bubbles. Put two stainless steel wire hooks in one end flange of the cavity. Place a stainless steel cross bar across the tank and hang the cavity from the bar using the hooks. Make sure the cavity is totally submersed in the water. There should be about an inch of water over the top of the upper flange.

f. Turn the ultrasonic on for five minutes. Shut the ultrasonic off. Once again, tip the cavity from side to side to remove all of the air bubbles generated during the degassing period.

g. Turn the ultrasonic on for 30 minutes .

h. Prepare the fifteen-gallon rinse bucket by locating the fifteen-gallon bucket to the left of the white rinse barrel. Doing so will allow easy access to the ultra sonic tank, the rinse barrel and the fifteen gallon bucket. Connect a clean Tygon ${ }^{\circledR}$ line from the D.I. hand valve located above the fifty-five gallon rinse barrel. Attach the other end of the Tygon $₫$ line to the hand valve near the bottom of the bucket. Fill the bucket until the water reaches two inches from the top rim. Connect the suction hose to the nipple near the top of the fifteengallon bucket.

i. After thirty minutes of cleaning, turn off the ultrasonic. Remove the cavity from the tank. Immediately proceed to the next step to prevent detergent from drying on the cavity.

j. This step requires two people. While one person holds the cavity over the rinse barrel, the 
other person should rinse the soap off with the spray wand.

k. Place the cavity in the fifteen-gallon bucket. Make sure it is fully submersed and the trapped air is removed by tipping it from side to side. Use one of the crossbars and two stainless steel wire hooks.

1. Simultaneously open the D.I. supply valve and open the hand valve at the bottom of the fifteen gallon bucket. Match the input flow with the suction line so the barrel does not overflow. The valve for the drain pump is located on the wall above the tall ultra sonic tank.

$m$. Place the resistivity meter near the drain line so it monitors the discharge. When the meter reads better than fourteen Mega ohms the cavity is thoroughly rinsed.

n. Remove the cavity from the fifteen-gallon bucket. Hang it under the HEPA Filter near the drying area. Blow all excess water from the cavity. Allow the cavity to dry for twenty-four hours.

4.0

ILLUSTRATIONS

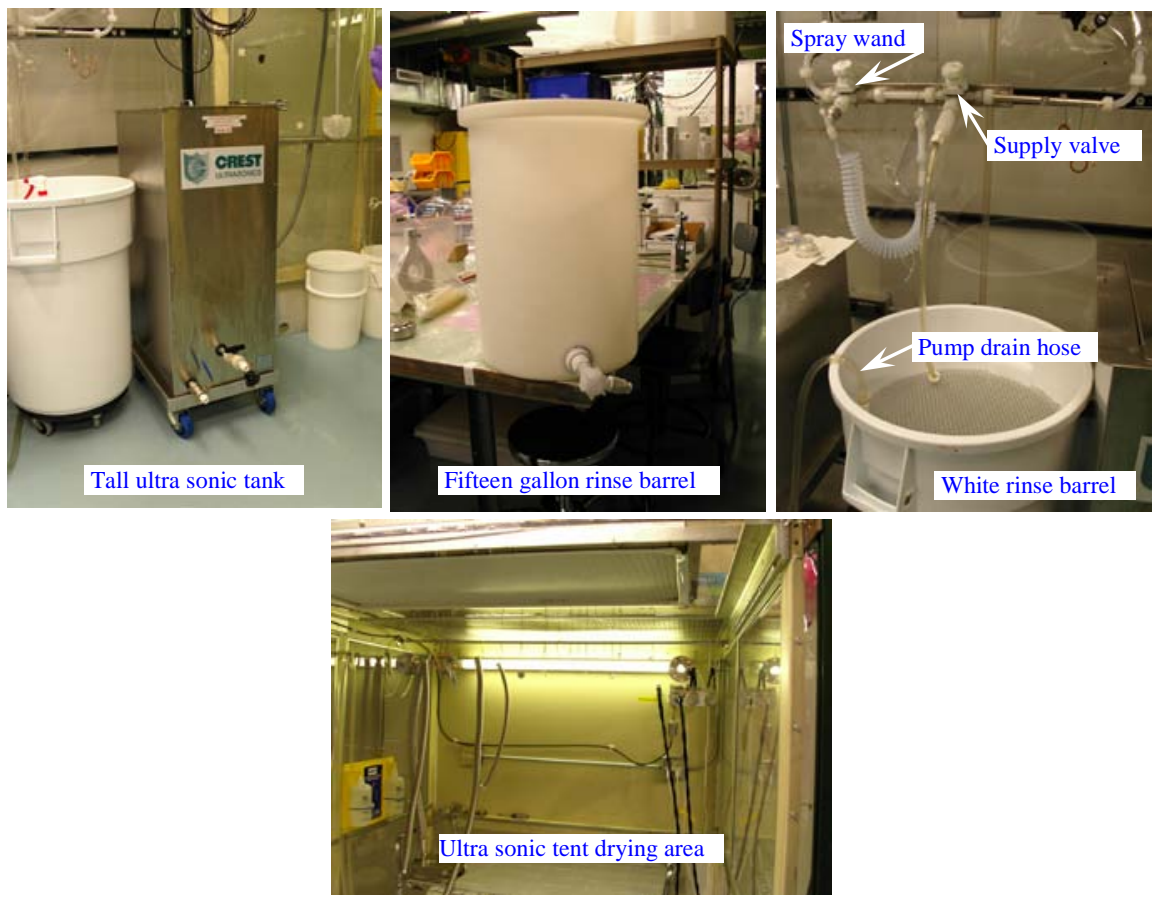

